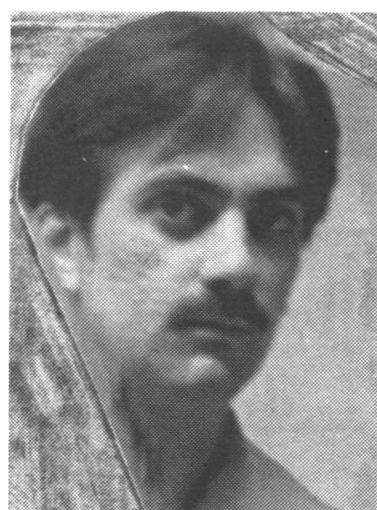

W. L. Kenney

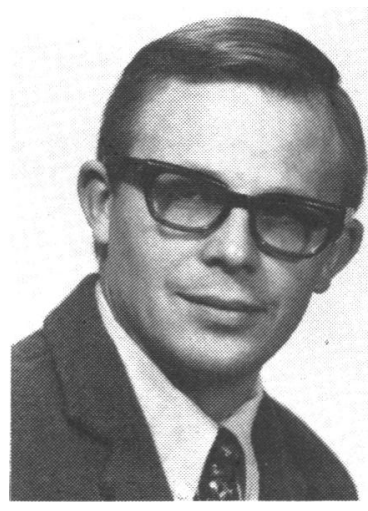

J. L. Hodgson

\title{
VARIABLES PREDICTIVE OF PERFORMANCE IN ELITE MIDDLE-DISTANCE RUNNERS
}

\author{
W. L. KENNEY, PhD and J. L. HODGSON, PhD \\ Laboratory for Human Performance Research, The Pennsylvania State University, University Park, PA 16802, USA
}

\begin{abstract}
The purpose of this study was to investigate possible factors which may account for differences in performance times within a closely-matched group (in terms of performance) of elite distance runners. The runners were training for competition in the 1984 Olympic Games in either the $5000 \mathrm{~m}$ or the $3000 \mathrm{~m}$ steeplechase events. Each runner's best performance time (BPT) was obtained and a stepwise regression analysis was performed with the following independent variables: age, weight, \% body fat, $\mathrm{VO}_{2}$ max, aerobic threshold (AerT), and anaerobic threshold (AnT). For the 5000 m-runners, a multiple correlation of age and AnT accounted for $77 \%$ of the variance ( $<<0.02)$; for the $3000 \mathrm{~m}$ steeplechase runners, body weight alone and body weight and AnT accounted for $94 \%(p<.01)$ and $98 \%(p<.05)$ of the variance, respectively. The results suggest that, among elite middle-distance runners, these parameters deserve attention as potential predictors of performance.
\end{abstract}

Key words: Elite distance runners, Prediction, $\mathrm{Age}_{1} \mathrm{VO}_{2}$ max, Aerobic threshold, Anaerobic threshold, Body weight, \% body fat.

\section{INTRODUCTION}

Physical and physiological characteristics of distance runners have received considerable attention in recent literature. Variables which have been associated with performance in distance running competition include maximal aerobic power (Costill, 1967; Davies and Thompson, 1979; Wyndham et al, 1969; Saltin and Åstrand, 1967), body composition (Costill et al, 1970; Novak et al, 1977; Sprynarova and Parizkova, 1971), various training indices (Hagan et al, 1981; Murray et al, 1980; Slovic, 1977), and running economy (Conley and Krahenbuhl, 1981). However prediction of performance times based on these and other parameters is often nebulous. For example, contrary to the traditional view that $\mathrm{VO}_{2}$ max is the criterion on which to base cardiovascular endurance, LaFontaine (1981) pointed out recently that published correlations between $\mathrm{VO}_{2} \max$ and performance range from 0.08 to 0.91 . An attempt to predict subtle performance differences in a homogeneous group of elite athletes is even more difficult. In the present study, possible predictors of best performance times for an elite group of $5000 \mathrm{~m}$ and $3000 \mathrm{~m}$ steeplechase (3000 s) runners were examined.

\section{METHOD}

\section{Subjects}

A total of 13 athletes was tested, eight 5000 m-runners and five $3000 \mathrm{~m}$ steeplechase runners. At the time of testing, all 13 were actively in training for these respective events for the 1984 Olympic Games, as part of the USOC Olympicdevelopment programme. Each was given a complete physical examination and gave informed consent to participate in the subsequent testing. Physical and physiological characteristics are given in Table I.

TABLE I

Physical and physiological characteristics of runners (mean \pm SEM)

\begin{tabular}{|c|c|c|c|c|c|c|c|}
\hline Event & $\mathbf{n}$ & $\begin{array}{l}\text { Age } \\
\text { (yrs) }\end{array}$ & $\begin{array}{l}\text { Weight } \\
\text { (kg) }\end{array}$ & $\begin{array}{c}\% \\
\text { Body } \\
\text { Fat }\end{array}$ & $\begin{array}{l}\mathrm{VO}_{2} \\
\max \end{array}$ & $\begin{array}{l}\text { Anaerobic } \\
\text { Threshold }\end{array}$ & $\begin{array}{c}\text { Best } \\
\text { performance } \\
\text { time } \\
\text { (BPT) } \\
\text { (min:sec) }\end{array}$ \\
\hline $5000 \mathrm{~m}$ & 8 & $\begin{array}{r}21.4 \\
\pm \quad 1.0\end{array}$ & $\begin{array}{r}64.5 \\
\pm \quad 2.4\end{array}$ & $\begin{array}{c}8.8 \\
\pm 0.8\end{array}$ & $\begin{array}{r}74.4 \\
\pm 1.3\end{array}$ & $\begin{array}{r}62.2 \\
\pm \quad 2.1\end{array}$ & $\begin{array}{r}14: 05 \\
\pm 0: 05\end{array}$ \\
\hline $\begin{array}{l}3000 \mathrm{~m} \\
\text { Steeplechase }\end{array}$ & 5 & $\begin{array}{r}22.0 \\
\pm 1.5\end{array}$ & $\begin{array}{r}71.9 \\
\pm \quad 1.0\end{array}$ & $\begin{array}{c}9.2 \\
\pm 0.5\end{array}$ & $\begin{array}{r}72.4 \\
\pm \quad 1.2\end{array}$ & $\begin{array}{r}58.0 \\
\pm \quad 2.1\end{array}$ & $\begin{array}{r}8: 38 \\
\pm 0: 06\end{array}$ \\
\hline
\end{tabular}

\section{Procedures}

Each subject was weighed under water to determine \% body fat and given a continuous running graded exercise test to determine ${\nabla \mathrm{O}_{2}}_{2}$ max. On a separate day, another graded exercise test was administered to determine both the aerobic (AerT) and anaerobic (AnT) thresholds (according to the definitions of Skinner and McLellan, 1980). The protocol of that test was as follows: After an initial warm-up period, treadmill speed was increased from 5.5 to $10 \mathrm{mph}$ at a rate of $0.5 \mathrm{mph} \mathrm{min-1}$. Thereafter, the grade was increased at a rate of $1 \%$ min-1 until approximate maximum heart rate was reached. Data were recorded breath-by-breath by an on-line computer system and $\mathrm{VE}$ vs $\mathrm{VO}_{2}$ and $\mathrm{VCO}_{2}$ vs $\mathrm{VO}_{2}$ 


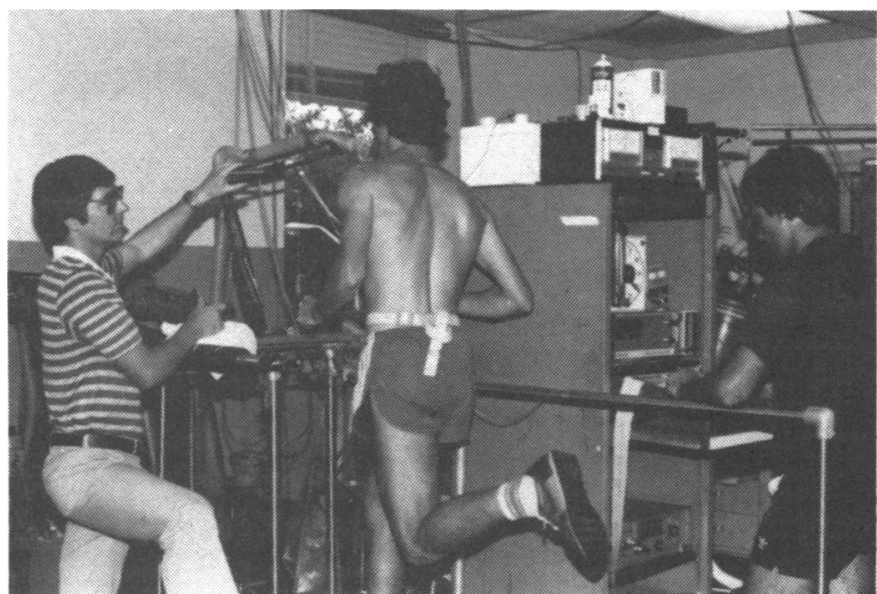

Dr. Kenney (right) and Dr. D. Kiser collecting breath-by-breath ventilatory data for AerT and AnT. The computerised system was developed at Noll Laboratory for Human Performance Research.

were plotted by computer for analysis. AerT and AnT were determined as the two points of inflection in these plots (Skinner and McLellan, 1980). Each runner's best performance time in seconds, in his best event (BPT 5000 or BPT 3000 s) was obtained and verified.

\section{Statistics}

A multiple linear regression analysis was performed which yielded the correlations seen in Table II. A correlation coefficient was considered significant if $p<0.05$.

TABLE ॥

Relationships of best performance times to measured variables

\begin{tabular}{|c|c|c|c|c|}
\hline Independent Variable & $\mathbf{R}^{\mathbf{2}}$ & $\begin{array}{l}\text { Signifi- } \\
\text { cance }\end{array}$ & $\mathbf{R}^{\mathbf{2}}$ & $\begin{array}{c}\text { Signifi- } \\
\text { cance }\end{array}$ \\
\hline & \multicolumn{2}{|c|}{$5000 \mathrm{~m}$} & \multicolumn{2}{|c|}{$3000 \mathrm{~m}$} \\
\hline Age (years) & 0.14 & NS & 0.50 & NS \\
\hline Weight (kg) & 0.15 & NS & 0.94 & $p<0.02$ \\
\hline$\%$ Body Fat & 0.29 & NS & 0.03 & NS \\
\hline $\mathrm{VO}_{2} \max \left(\mathrm{ml} \cdot \mathrm{kg}^{-1} \mathrm{~min}^{-1}\right)$ & 0.08 & NS & 0.16 & NS \\
\hline An Threshold (ml. $\left.\mathrm{kg}^{-1} \mathrm{~min}^{-1}\right)$ & 0.12 & NS & 0.35 & NS \\
\hline Age and An Threshold & 0.98 & $p<0.02$ & 0.98 & $p<0.05$ \\
\hline
\end{tabular}

\section{RESULTS AND DISCUSSION}

As seen in Table I, the athletes in this study represented a fairly homogenous group in terms of physical and physiological characteristics. They were also closely matched in terms of best times in $5000 \mathrm{~m}$ (SEM $=5$ seconds) and $3000 \mathrm{~m}$ steeplechase events (SEM $=6 \mathrm{sec}-$ onds). As a group, they can be characterised as having ectomesomorphic body builds, high maximal aerobic capacities, and slightly below average body weights. Their ages ranged from 19 to 26 , with a high age indicative of greater competitive running experience (personal observation).

The relationships between performance time and the independent variables studied are shown in Table II. None of the correlations for the $5000 \mathrm{~m}$ group was significant and only the relationship between total body weight and BPT $3000 \mathrm{~s}$ was significant $(p<0.01)$. The correlations between $\mathrm{VO}_{2}$ max and performance $(r=0.28$ and 0.40$)$ were much lower than earlier investigators who used less homogeneous groups over distances from $7.5 \mathrm{~km}(4.7 \mathrm{mi})$ to $15 \mathrm{~km}$ (9.4 mi) (Costill, 1967; Costill et al, 1973; Foster et al, 1977; Foster et al, 1978). However, Conley and Krahenbuhl (1981) recently obtained a correlation of $r=-0.12$ with a subject population which was similar in homogeneity (for performance and $\mathrm{VO}_{2} \max$ ) to the present group. Our correlation carried a positive sign, indicated that there was a small, albeit insignificant, inverse relationship between $\mathrm{VO}_{2}$ and performance. This does not argue that $\mathrm{VO}_{2} \max$ is unimportant, as evidenced by the high levels exhibited by all members of the group, but that a given elite level of competition, a higher $\mathrm{VO}_{2}$ max does not determine success in a race of this distance.

The best prediction equation of BPT 5000 contains the independent variables of age and AnT (BPT $5000=1155-5.4$ (age) -2.9 (AnT)). The older runners had been training longer and had a greater advantage in terms of both years and level of competition. Thus, it appears that, within the age span of these runners, older (more experienced) runners who could delay onset of lactate formation (as evidenced by high AnT) did better in competitive $5000 \mathrm{~m}$ races.

In the $3000 \mathrm{~m}$ steeplechase group, body weight alone accounted for $94 \%$ of the variation in performance time (BPT $3000 \mathrm{~s}=93.4+5.9$ (wt), $p<0.01$ ). Addition of AnT to the equation (BPT $3000 \mathrm{~s}=99+5.4$ (wt) +0.6 (AnT)) increased the $R_{2}$ value to $98 \%$. (However, due to the small sample size, the extra variable decreased the significance level somewhat).

Thus, it appears that for the small, homogeneous group of runners studied, age, AnT and body weight are important variables in predicting best performance time in competitive $5000 \mathrm{~m}$ and $3000 \mathrm{~m}$ steeplechase races. Other variables not studied here, e.g., running economy (Conley and Krahenbulh, 1981), and training indices (Hagen et al, 1981) have shown similar predictive usefulness.

\section{CONCLUSIONS}

The present study merits the following conclusions:

1. A high aerobic capacity is a prerequisite for entry into an "elite" class of distance runners. However, among these runners, $\mathrm{VO}_{2}$ max does not determine success in a competitive running event.

2. Within a highly-trained, homogeneous population of $5000 \mathrm{~m}$ runners, age (within the range of the present study) and anaerobic threshold accounted for a large and significant amount of variation $(77 \%)$ in peak performance. In $3000 \mathrm{~m}$ steeplechasers, low total body weight alone accounted for $94 \%$ of the variation; body weight and AnT accounted for $98 \%$.

3. It is recommended that, within such a group of athletes possessing equally-high aerobic capacities, age (experience), low body weight, and high anaerobic threshold are important attributes for successful performance.

\section{References}

Conley, D. L. and Krahenbuhl, G. S., 1981 "Running economy and distance running performance of highly trained athletes". Medicine and Science in Sports and Exercise 12: 357-360.

Costill, D. L., 1967 "The relationship between selected physiological variables and distance running performance". Journal of Sports Medicine and Phys. Fitness 7: 61-66.

Costill, D. L., Bowers, R. and Kammer, W. F., 1970 "Skinfold estimates of body fat among marathon runners". Medicine and Science in Sports 2: 93-95.

Costill, D. L., Thomason, H. and Roberts, E., 1973 "Fractional utilization of the aerobic capacity during distance running". Medicine and Science in Sports 5: 248-252

Davies, C. T. M. and Thompson, M. W., 1979 "Aerobic performance of female marathon and male ultramarathon athletes". European Journal of Applied Physiology 41: 233-252.

Foster, C., Costill, D. L., Daniels, J. T. and Fink, W. J., 1978 "Skeletal muscle enzyme activity, fibre composition and $\mathrm{VO}_{2}$ max in relation to distance running performance". European Journal of Applied Physiology 29: 73-80.

Foster, C., Daniels, J. T. and Yarbrough, R. A., 1977 "Physiological and training correlates of marathon running performance". Aust.Journal of Sports Medicine 8: 14-17.

Hagan, R. D., Smith, M. G. and Gettman, L. R., 1981 "Marathon performance in relation to maximal aerobic power and training indices". Medicine and Science in Sports Exercise 13: 185-189. 
LaFontaine, J. P., Londeree, B. R. and Spath, W. K., 1981 "The maximal steady state versus selected running events". Medicine and Science in Sports and Exercise 13: 190-193.

Murray, T. D., Zinkgraf, S. A. and Shea, C., 1980 "The relationship of selected training variables on performance in marathon running". Medicine and Science in Sports and Exercise 12: 81 (abstract).

Novak, L. P., Woodward, W. A., Bestit, C. and Mellerwicz, H., 1977 "Working capacity, body composition, and anthropometry of Olympic female athletes". Journal of Sports Medicine and Physical Fitness 17: 275-283.

Saltin, B. and Astrand, P. O., 1967 "Maximal oxygen uptake in athletes". Journal of Applied Physiology 23: 353-358.
Skinner, J. and McLellan, T., 1980 "The transition from aerobic to anaerobic metabolism". Research Quarterly for Exercise and Sport 51: 234-248.

Slovic, P., 1977 "Empirical study of training and performance in the marathon". Research Quarterly for Exercise and Sport 48: 769-777.

Sprynarova, S. and Parizkova, J., 1971 "Functional capacity and body composition in top weight-lifters, swimmers, runners, and skiers". International Zeitschrift für angewrodte Physiologie, 24: 184-194.

Wyndham, D. H., Strydom, N. B., Von Rersburg, A. J. and Borade, A. J. S., 1969 "Physiological requirements for world-class performance in endurance running". South African Medical Journal 43: 996-1002.

\title{
BOOK REVIEW
}

Title: RACE HORSE TRAINING AND FEEDING

$\begin{array}{lll}\text { Author: } & \text { Dr. Philip Swann } \quad 1984 \quad \text { ISBN 0-9590433-0-6 }\end{array}$

Publisher: $\quad$ Race Horse Sportsmedicine and Scientific Conditioning, PO Box 12, DOREEN, Victoria 3754, Australia

Price: \$Aust. $20+5$ p. \& p. 145 pages Soft cover Illustrated with half-tone photographs

This book is written essentially for the trainer of Australian and American flat race and trotting race horses, but the information given could be of value to the British trainer, point-to-point or hunter owner, and to those in European centres of trotting such as Austria.

The author applies the technique of modern human athletic training, based on muscle and cardio-respiratory physiology, to the training of the elite equine "athlete", an approach long overdue. He compares the $7 \%-15 \%$ improvement in human athletics in the past 25 years with only $1 \%-3 \%$ in equine performance. Anaerobic training is described using heart rate monitoring to aim at increasing speed with a heart rate of around 150 beats a minute (from a pre-exercise level of 35 ) and heart-rate meters are now available. The 150/min HR reaches the anaerobic threshold. More specific schedules are given to develop slow-twitch muscle fibres by distance work, then strenuous pace work to increase speed and stamina at steady state, developing fast-twitch fibres, and finally speed work, largely anaerobic, at HR $>150$, by interval training. Horses, however, unlike humans, should not be trained to exhaustion. Special types of training, such as swimming, especially in rehabilitation after injury, are mentioned. The physiological reasons for the schedules are given in terms that should easily be understood by the layman.

Diet is discussed in detail, but the hundredweight of grain each eight to ten days needed for the race horse is beyond the pocket of the recreational rider, nor is it really necessary in this quantity. The chapter on drugs has several weaknesses, or rather missed opportunities. The author, although mentioning adverse effects of doping, fails to state that in international rules of racing even a trace of a prohibited drug is enough to have the horse banned, and the presence of theobromine from a chocolate tit-bit or from cattle cake made from chocolate-bean husks fed to point-to-pointers has led to heavy penalties.

This book is recommended to the owner of a competition horse, whether a point-to-point hunter or a child's gymkhana pony, as few doctors or physiotherapists own a race horse, though many are concerned with horses and ponies in some sort of training. To the non-horse owner the action photographs include some of dramatic accidents, illustrating the aetiology of human injuries. The need for better head protection is stressed. I am only sorry that this book was not written before my stable and paddock were empty. My daughter would have found it of considerable value.

H. E. Robson

\section{BOOK REVIEW}

\author{
Title: $\quad$ MANUAL MEDICINE 1984 \\ Editors: $\quad$ J. Dvorak, V. Dvorak and W. Schneider \\ Publisher: $\quad$ Springer-Verlag, Berlin \\ Price: $£ 28.80$
}

This book contains the results of a seminar held in Fischingen, Switzerland, attended by 32 international specialists in Manual Medicine (in this context a combination of osteopathic medical practice and the latest American concept of muscle energy treatment techniques as propounded by Philip Greenman, D.O. Michigan State University).

It attempts to define treatment terminology such as 'mobilisation' and 'manipulation', and offer a multinational view, at times not only at variance but also at opposite extremes to each other, of a large number of examination and 'manipulative' procedures directed to the spine. A basic knowledge and groundwork in osteopathic practice is, in my view, essential before tackling this book, which is in danger of convincing the uninitiated of the requirement for "peaceful co-existence" in this branch of medicine as well as in East-West political confrontation in the 1980's.

For those with basic grounding in Manual Medicine the wide range of techniques demonstrated will add an interesting dimension though strictly in an osteopathic sense, without any direction towards other managements such as traction or injections. 